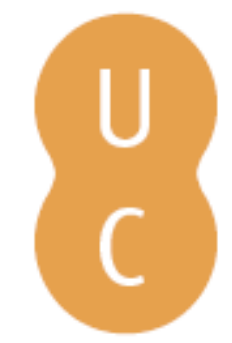

\title{
pommalina
}

\section{A sustentabilidade da produção de biodiesel a partir de óleos alimentares usados: 0 caso da freguesia de Ericeira}

Autor(es): $\quad$ Caseiro, Cláudia; Roxo, Maria José

Publicado por: Imprensa da Universidade de Coimbra

URL

persistente: URI:http://hdl.handle.net/10316.2/31190

DOI: $\quad$ DOI:http://dx.doi.org/10.14195/978-989-26-0244-8_89

Accessed : $\quad$ 26-Apr-2023 01:20:10

A navegação consulta e descarregamento dos títulos inseridos nas Bibliotecas Digitais UC Digitalis, UC Pombalina e UC Impactum, pressupõem a aceitação plena e sem reservas dos Termos e Condições de Uso destas Bibliotecas Digitais, disponíveis em https://digitalis.uc.pt/pt-pt/termos.

Conforme exposto nos referidos Termos e Condições de Uso, o descarregamento de títulos de acesso restrito requer uma licença válida de autorização devendo o utilizador aceder ao(s) documento(s) a partir de um endereço de IP da instituição detentora da supramencionada licença.

Ao utilizador é apenas permitido o descarregamento para uso pessoal, pelo que o emprego do(s) título(s) descarregado(s) para outro fim, designadamente comercial, carece de autorização do respetivo autor ou editor da obra.

Na medida em que todas as obras da UC Digitalis se encontram protegidas pelo Código do Direito de Autor e Direitos Conexos e demais legislação aplicável, toda a cópia, parcial ou total, deste documento, nos casos em que é legalmente admitida, deverá conter ou fazer-se acompanhar por este aviso.

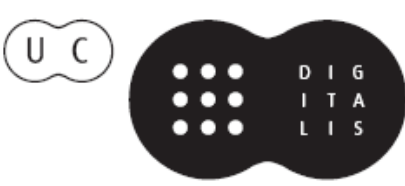




\section{TRUNFOS DE UMA}

\section{EOGRAFIA ACIVA}

\section{DESENVOLVIMENTO LOCAL,}

AMBIENTE,

ORDENAMENTO

E TECNOLOGIA

Norberto Santos

Lúcio Cunha

COORDENAÇÃO 
Cláudia Caseiro, Maria José Roxo

e-GEO - Centro de Estudos de Geografia e Planeamento Regional, Faculdade de Ciências Sociais

e Humanas, Universidade Nova de Lisboa

\section{A SUSTENTABILIDADE DA PRODUÇÃO DE BIODIESEL A PARTIR DE ÓLEOS ALIMENTARES \\ USADOS: O CASO DA FREGUESIA DA ERICEIRA}

\section{INTRODUÇÃO}

Ao longo da história da Humanidade, o uso de energia sempre foi indispensável para o crescimento económico e desenvolvimento dos países, assim como para a melhoria da qualidade de vida das populaçóes, pelo acréscimo do conforto, das facilidades de deslocação, da qualidade do trabalho, entre muitos outros aspectos.

A posse de fontes de energia e a capacidade de produzi-la tem sido uma das metas mais desejadas pelos Governos actuais, tendo motivado, nas últimas décadas, o forte investimento na pesquisa e no desenvolvimento de novas fontes energéticas alternativas, de modo a diversificar a oferta.

No entanto, de toda a energia primária consumida no Mundo, cerca de $80 \%$ continua a provir do petróleo, carvão e do gás natural, tendo esse valor atingido os $88 \%$ em 2008 (BP, 2009). Estas fontes de energia designadas por combustíveis fósseis são limitadas e, se os padróes de consumo se mantiverem ao ritmo actual, prevê-se dificuldades no abastecimento futuro.

Neste contexto, o biodiesel surge como uma das fontes de energia alternativa mais estudadas na actualidade, caracterizando-se por ser um combustível biodegradável produzido a partir de matérias-primas naturais e renováveis, como os óleos vegetais, as gorduras animais e os óleos e gorduras residuais, através de um processo químico designado de transesterificação (Torres et al., 2006 e Lima, 2004). Deste processo resulta um combustível de qualidade que pode substituir o óleo diesel fóssil - gasóleo - em qualquer motor diesel.

\section{A PROdUÇÃo de BiOdiesel EM PORTUGAL NO CONTEXTO DA UNIÃo EUROPEIA}

No início dos anos 90 do século passado, o processo de industrialização do biodiesel iniciou-se na Uniáo Europeia (UE), tendo como responsáveis a Alemanha, a França e a Itália. Para tal muito contribui o facto de nestes países, a partir de 1992, passar a existir a possibilidade de se efectuar culturas com fins não alimentares nas terras retiradas da produção, por via das restriçóes impostas pela Política Agrícola Comum. 
Para além desse facto, factores que ocorreram à escala global e se continuam a registar actualmente, dos quais se destacam a excessiva dependência e custos energéticos face às importaçóes petrolíferas, bem como o aumento das preocupaçóes de natureza ambiental, sobretudo nos países desenvolvidos, incentivaram e continuam a fomentar a produçáo de biodiesel não só na UE, mas também um pouco por todo o Mundo.

Assim, segundo o European Biodiesel Board - EBB (2009), a UE produziu em 2008 aproximadamente 7.755 milhóes de toneladas de biodiesel, o que correspondeu a cerca de $54 \%$ da produção mundial nesse ano.

Este valor foi alcançado com uma forte contribuição da Alemanha e da França, sendo que a Alemanha é actualmente o maior produtor e consumidor mundial de biodiesel, responsável por $20 \%$ da produção em 2008 (2.819 milhóes toneladas), a França o segundo maior produtor na UE e o terceiro a nível mundial, a seguir à Alemanha e aos Estados Unidos da América, representando 13\% do total mundial (1.815 milhóes de toneladas).

A UE tem registado de ano para ano um elevado aumento na sua produção e é actualmente o maior produtor de biodiesel, à escala mundial, o que se justifica pela forte aposta que tem sido feita neste produto. O Projecto de Demonstração de Biodiesel implementado durante a década de 90 do século passado reflecte essa aposta, tendo a UE aplicado cerca de 100 milhóes de euros neste projecto, considerado o mais relevante de todos os programas europeus de bioenergia.

Portugal só iniciou o processo de produção de biodiesel em 2005, tendo produzido apenas mil toneladas deste produto nesse ano (EBB, 2009). Tem portanto um passado muito recente no sector do biodiesel e dos biocombustíveis, em geral, devendo-se este atraso à existência de diversos condicionalismos na produção deste produto.

Alguns dos principais constrangimentos ao seu fabrico são a baixa produtividade agrícola, essencialmente, por questóes inerentes ao tipo de solos e aos processos de cultivo, a escassez de terra disponível para cultivo da matéria-prima, o custo elevado do seu processamento industrial e a falta de projectos-piloto que demonstrem, junto dos actores da fileira, os problemas e as soluçóes associados à produção e uso deste biocombustível.

Contudo, nos últimos anos tem-se verificado já um acréscimo bastante considerável da produçáo de biodiesel. Produzindo sobretudo a partir de óleos extraídos de plantas como o girassol, a palma, a soja e a colza, e mais recentemente a partir de óleos alimentares usados, Portugal aumentou a produçáo de 91 mil toneladas, em 2006, para 175 mil toneladas, em 2007, e para 268 mil toneladas, em 2008, alcançando o sexto lugar no ranking de produtores da UE (EBB, 2009).

\section{A SUSTENTABILIDADE DA PRODUÇÃO DE BIODIESEL A PARTIR DE ÓlEOS ALIMENTARES USADOS}

\subsection{Matéria-prima - Óleos Alimentares Usados}

Os óleos alimentares usados constituem uma categoria de resíduos derivados de diversas actividades, mas, na sua maioria, são provenientes da actividade de fritura de alimentos, essencialmente da utilização de óleos de origem vegetal como o azeite, o óleo de girassol, o óleo de soja, entre outros. 
De acordo com as «Linhas de Definição Estratégica do Sistema de Gestão dos Óleos Alimentares Usados» (Inovação e Projectos em Ambiente, 2004), em Portugal são produzidos anualmente cerca de 125.000 toneladas deste produto, dos quais apenas 3.500 toneladas são recolhidas, tendo sido utilizadas, sobretudo, na produçáo de massa consistente lubrificante, sabão e rações animais. Os restantes resíduos são, na sua maioria, depositados na rede de esgotos, provocando diversos impactos ambientais, como a contaminação das águas e dos solos.

Perante este panorama a reutilização de óleos alimentares usados tem-se mostrado uma opção interessante, como matéria-prima para a produção de biodiesel, visto que aproveita o óleo vegetal só após a sua utilização noutra actividade, tendo assim este produto um segundo uso. Deste modo a reutilização dos óleos atenderia à solução de duas necessidades de uma só vez, pois retiraria do Ambiente um resíduo poluente e ainda permitiria a produção de uma fonte de energia alternativa.

Para além dos aspectos referidos, este tipo de matéria-prima não apresenta nenhum dos impactos comuns às culturas energéticas (milho, arroz, soja) utilizadas para produzir biodiesel, como os problemas resultantes da alteração do uso dos solos, dos quais a desflorestação, erosão dos solos e perda de biodiversidade são exemplos; a contaminação dos solos e da água, derivada do uso de fertilizantes e pesticidas; a sobreexploração dos recursos hídricos, decorrente da intensa necessidade de irrigação destas culturas; e ainda o facto de competirem directamente com a produçâo de alimentos.

\subsection{Viabilidade Económica}

O biodiesel sendo uma fonte de energia renovável, alternativa ao gasóleo, pode dar um contributo importante para a redução da dependência dos combustíveis fósseis, o que é, por si só, um dos maiores incentivos económicos à produção deste combustível, visto cada vez mais o preço de todos os derivados do petróleo tender a subir.

O custo do processo industrial é outro factor que muito contribuiu para a viabilidade económica deste produto, sendo apenas necessário para converter os óleos vegetais em biodiesel a presença de álcool, como metanol ou etanol, que representa $12 \%$ desta reacção, e de um catalisador para acelerar o processo, que corresponde a 1\% (Methanol Institute and International Fuel Quality Center, 2006). O álcool utilizado pode ser ainda reaproveitado várias vezes, desde que se proceda à recuperação e desidratação do mesmo.

O facto do biodiesel poder ser utilizado directamente nos motores, sem se ter de recorrer a qualquer adaptação ou alteração mecânica é também um factor de extrema importância na viabilização económica deste combustível (Bozbas, 2005). A incorporação de pequenas porçôes deste produto nos veículos, para além de não implicar qualquer problema no seu desempenho, aumenta a vida útil dos motores e reduz a necessidade de manutenção, uma vez que a sua capacidade lubrificante é superior à do gasóleo (Pedrotti, 2006).

No entanto, tal só é possível se o biodiesel utilizado, quer em estado puro como em mistura, atender às normas de qualidade estabelecidas para assegurar um desempenho óptimo dos motores. Neste sentido a qualidade do biodiesel produzido é um factor de extrema importância que define o modo de funcionamento e o tempo de vida de um motor (Maurício, 2008). 
Outro factor não menos importante para a viabilização económica deste biocombustível é o facto do rendimento energético do biodiesel ser essencialmente o mesmo que o do gasóleo. A energia específica do biodiesel é apenas cerca de $5 \%$ inferior à do gasóleo (Maurício, 2008).

Apesar deste combustível ser uma alternativa tecnicamente viável ao gasóleo, o seu custo de produção é 1,5 a 3 vezes superior à deste último, o que o torna menos competitivo, se não forem consideradas as externalidades positivas, como as vantagens ambientais e a criação de emprego.

Porém, o preço da matéria-prima representa cerca de $85 \%$ do custo final deste produto, portanto, quando a matéria-prima utilizada são os óleos alimentares usados, os custos de produçáo de biodiesel diminuem drasticamente, pois, ao contrário dos restantes óleos vegetais utilizados, onde se registam elevados custos no cultivo das plantas de onde vão ser extraídos, apenas se tem de considerar os custos da sua recolha.

Neste sentido, de acordo com Lima (2004), se a matéria-prima utilizada for óleo alimentar usado, o custo de produçáo será de apenas $0,18 € /$ litro, valor bastante mais baixo que o do gasóleo, cerca de 1,053 €/litro.

É de salientar ainda que a reutilização dos óleos alimentares usados para produção de biodiesel reduzirá bastante os custos de manutenção das Estações de Tratamento das Águas Residuais, evitando os problemas de entupimento das canalizaçóes que ocorriam devido ao constante depósito destes resíduos na rede de esgoto.

\subsection{Vantagens para o Ambiente}

Apesar da produção de biodiesel a partir de óleos alimentares usados apresentar benefícios nas três dimensôes do Desenvolvimento Sustentável (económica, social e ambiental) as vantagens ambientais deste produto são as que mais têm incentivado a sua produção e utilização.

Para Zhang et al. (2003, p. 1) «Biodiesel, derived from vegetable oil or animal fats, is recommended for use as a substitute for petroleum-based diesel mainly because biodiesel is a renewable, domestic resource with an environmentally friendly emission profile and is readily biodegradable».

O biodiesel é então considerado um combustível renovável e biodegradável, ao decompor-se biologicamente com facilidade e, no caso de se registar um acidente, não existir perigo de contaminação dos solos ou das águas (Fangrui \& Milford, 1999).

Para além disso, não é um combustível perigoso pois tem um risco de explosão bastante baixo, suportando uma fonte de calor até 150 graus Célsius sem explodir, possibilitando facilidade no transporte e armazenamento. É de referir também que não é prejudicial para a saúde pública, pois não contém benzóis ou outros componentes poliaromáticos carcinogénicos.

No entanto, a principal vantagem apontada ao biodiesel é o facto de ser pouco poluente, pois reduz em $78 \%$ as emissóes de $\mathrm{CO}_{2}$, em $90 \%$ as emissóes de fumaça e elimina quase na sua totalidade as emissóes de óxido de enxofre $(<0,001 \%)$ para a atmosfera, permitindo diminuir também as emissóes de $\mathrm{SO}_{2}$ (Lima, 2004). Assim a sua utilização diminuiria a poluição atmosférica e o impacto no efeito de estufa seria mínimo em comparação com o do gasóleo. 
Contudo, de acordo com a Environmental Protection Agency (2002), apesar da utilização de biodiesel reduzir efectivamente as emissóes de monóxido de carbono, de material particulado e dos hidrocarbonetos totais que contêm um elevado potencial cancerígeno, aumenta as emissões de óxido de nitrogénio. Porém este aumento é pouco significativo quando comparado com a redução das restantes emissóes, por exemplo, numa mistura de $20 \%$ de biodiesel o monóxido de nitrogénio aumentará em apenas $2 \%$, enquanto as emissóes de monóxido de carbono serão reduzidas em $11 \%$ e as de hidrocarbonetos totais em $21,1 \%$. É de mencionar igualmente que a utilização de catalisadores, já criados pela indústria automóvel, poderá minimizar as emissóes de monóxido de nitrogénio.

\subsection{Benefícios sociais}

Actualmente, o processo de produção de biodiesel é visto como uma fonte geradora de emprego em todo o Mundo, o que tem sido apontado, a nível social, como um grande incentivo para o fabrico deste produto. Por um lado, as unidades de produção de biodiesel necessitam de um elevado número de trabalhadores, uma vez que são indústrias de trabalho intensivo. Por outro, a produçáo de biodiesel, nomeadamente a partir de óleos alimentares usados, é um processo composto por várias actividades distintas, o que implica a utilização de uma mão-de-obra diversificada.

Outro aspecto bastante importante relacionado com a componente social da produção deste biocombustível é o facto da sua utilização, em detrimento do uso de combustíveis fósseis, permitir a poupança de verbas que são gastas actualmente na prospecção de petróleo. Esse capital poderia ter um fim social melhor, pois a produção de biodiesel não requer esse tipo de investimento.

É de referir ainda que à medida que a utilização de biodiesel for substituindo progressivamente parte do consumo de gasóleo, poderá vir a observar-se uma situação de maior estabilidade política e social no Mundo, uma vez que a grande concentração da matériaprima (petróleo) para a produção deste combustível se encontra em países de elevada instabilidade, o que tem resultado num sentimento de insegurança global.

\section{A UTILIZAÇÃo DE Óleos alimentares usados PARA PRODUÇÃo DE BIODIESEL NA FREGUESIA DA ERICEIRA}

Em 2006, para minimizar os problemas resultantes do aumento do volume de resíduos, a Freguesia da Ericeira ${ }^{1}$ iniciou o «Projecto Ericeira Recicla». Esta iniciativa consiste na recolha personalizada, porta a porta, de diversos tipos de resíduos, como restos orgânicos, papel, vidro, embalagens, óleos alimentares usados e rolhas de cortiça, produzidos pelos estabelecimentos da freguesia. Actualmente colaboram neste projecto 47 estabelecimentos.

Como já foi mencionado, os óleos alimentares usados são um dos tipos de resíduos recolhidos nesta iniciativa, tendo a sua recolha como principais objectivos reduzir o im-

\footnotetext{
${ }^{1}$ A Freguesia da Ericeira é uma das dezassete freguesias pertencentes ao Concelho de Mafra e integra a Área Metropolitana de Lisboa. Tinha em 2001 uma população de 6.597 habitantes e prevê-se que em 2011 atinja os 9.552 habitantes, registando um crescimento populacional de aproximadamente $45 \%$.
} 
pacto destes óleos no ambiente e ainda, através da sua reutilização como matéria-prima para produzir biodiesel, minimizar os impactos ambientais resultantes do uso de combustíveis fósseis pelas viaturas desta autarquia. Neste sentido, o biodiesel produzido serve para abastecer as viaturas da Junta de Freguesia e ceder o excedente a outras instituiçóes e colectividades do município de Mafra.

Todo o processo de produçáo do biodiesel é feito em instalaçốes da Junta de Freguesia que é a responsável, quer pelo seu fabrico, como pela sua gestão. Do processo de transformaçáo dos óleos alimentares usados em biodiesel resulta ainda um subproduto - a glicerina, que é utilizada para lavagem de estradas, viaturas, madeiras e em todo o tipo de máquinas.

Paralelamente a esta iniciativa, e com o intuito de se recolher uma maior quantidade de óleos alimentares usados para se aumentar a produçáo de biodiesel, procedeu-se à colocaçáo de óleóes por toda a freguesia, de modo a que a população em geral pudesse também depositar os óleos que utiliza no seu consumo doméstico. Actualmente a população dispóe de 22 óleóes na vila da Ericeira e dois em aldeias pertencentes a esta freguesia.

Com a implementação destas duas iniciativas em conjunto, recolheram-se em 2006 um total de cerca de 16.000 litros de óleos alimentares usados que, posteriormente, foram utilizados para produzir biodiesel. Já em 2007 registaram-se 35.610 litros deste produto e em 200838.015 litros, o que comprova o crescente sucesso desta iniciativa, uma vez que em ambos os anos foi depositado mais do dobro da quantidade de óleo do que em 2006.

Parte do sucesso desta iniciativa deve-se à forte campanha de sensibilização e informação que a autarquia desenvolveu durante a implementação destes projectos, assente sobretudo na distribuição de folhetos a toda a população e na realizaçáo de campanhas de divulgação em locais públicos estratégicos, como o Largo das Ribas e a Praça da República, local que se pode observar na Figura 1.

Figura 1 - Campanha de sensibilização sobre a recolha de óleos alimentares usados na Ericeira.

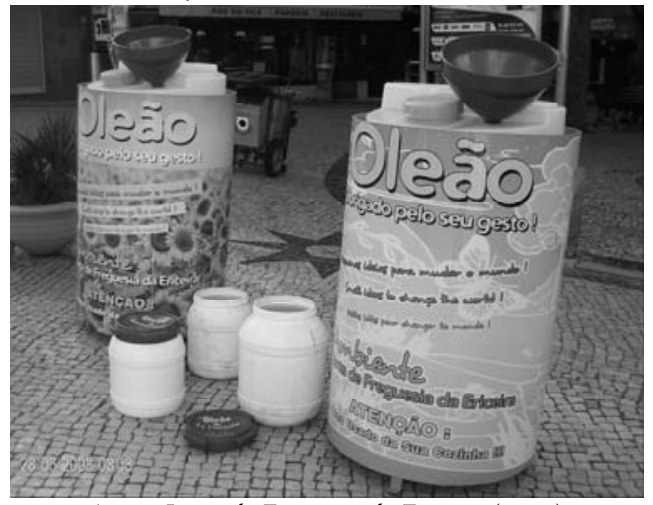

Autor: Junta de Freguesia da Ericeira (2008)

Com a implementação destas duas iniciativas, a autarquia da Ericeira conseguiu que três das suas viaturas (Figura 2), passassem a utilizar 100\% biodiesel, como combustível, e que outras cinco utilizassem uma mistura composta por $80 \%$ deste produto e $20 \%$ de gasóleo.

Deste modo, com estas iniciativas a Freguesia da Ericeira conseguiu não só tornar-se mais auto-suficiente energeticamente e utilizar um combustível menos poluente, como 
reutilizar um resíduo nocivo, resolvendo os problemas de entupimento e obstrução das tubagens nas ETAR's, associados ao seu depósito na rede de esgotos, e o impacto que tinha no ambiente, do qual se destaca a poluição e contaminação dos solos e das águas.

Figura 2 - Viatura da Junta de Freguesia da Ericeira a biodiesel.

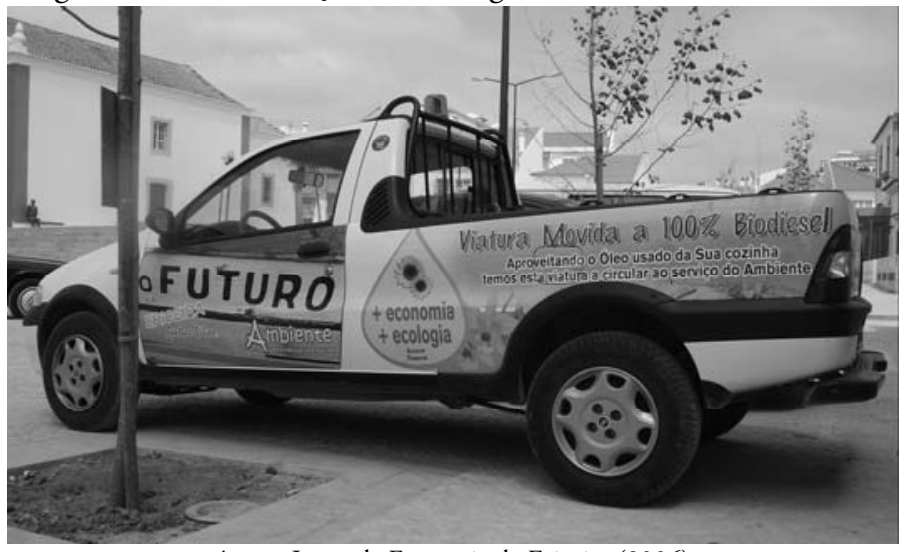

Autor: Junta de Freguesia da Ericeira (2006)

A utilização do biodiesel em detrimento do gasóleo nas viaturas da autarquia permite ainda a esta poupar aproximadamente 1.020 euros mensalmente, uma vez que estas viaturas consumiam aproximadamente 850 litros de gasóleo por mês, que são agora substituídos pelo biodiesel produzido, o que totaliza uma poupança de cerca de 12.240 euros por ano.

O restante biodiesel é doado, sendo que mensalmente cerca de 450 litros de biodiesel são repartidos por diversas instituiçóes do município de Mafra. A autarquia da Ericeira coloca também à disposiçáo da populaçáo cinco litros de biodiesel para quem desejar experimentar no seu veículo, sendo esta mais uma maneira de fomentar a participaçáo neste processo de reciclagem.

A Junta de Freguesia da Ericeira pretende a curto-prazo intensificar a recolha de óleos alimentares usados, com o objectivo de aumentar a quantidade recolhida, situada normalmente entre os 2.000 e os 3.000 litros mensais, para mais de 5.000 litros mensais, o que resultaria na disponibilidade de mais de 60.000 litros por ano para produção de biodiesel.

\section{CONSIDERAÇŌES FINAIS}

O biodiesel produzido a partir de óleos alimentares usados afigura-se como um combustível promissor pelos benefícios que apresenta a nível ambiental, económico e social. Em primeiro lugar, pela importância ambiental da sua utilizaçáo, sobretudo pela efectiva redução dos gases com efeito de estufa e, consequentemente, dos níveis de poluição atmosférica; em segundo, como fonte estratégica de energia renovável alternativa ao gasóleo, contribuindo para a redução do consumo de combustíveis fósseis; e por último, pelos benefícios sociais que a sua produção e comercialização trazem, dos quais é de destacar a criação de diversos postos de trabalho. 
A Junta da Ericeira, contando com a colaboração e o empenho dos seus moradores e a participação dos estabelecimentos comerciais da freguesia, tornou possível a reintroduçáo no ciclo económico de um tipo de resíduo táo poluente e perigoso como os óleos alimentares usados. Através do reaproveitamento destes resíduos para produzir biodiesel, esta autarquia para além de minimizar o impacto ambiental destes e do uso de combustíveis fósseis no seu território, conseguiu ainda, ao abastecer alguns dos veículos da sua frota com biodiesel, evitar uma parte considerável das despesas que tinha em combustível.

Exemplos como este, fazem acreditar que, com uma maior consciencialização colectiva para a reutilização de resíduos, nomeadamente dos óleos alimentares usados, quer por parte da população, como dos decisores políticos, é possível que o biodiesel, produzido a partir destes materiais, tenha de facto um importante contributo a nível ambiental, económico e social no panorama energético nacional.

\section{REFERÊNCIAS BIBLIOGRÁFICAS}

Bozbas, K. 2005, «Biodiesel as an alternative motor fuel: Production and policies in the European Union», Renewable and Sustainable Energy Reviews, no 12, pp. 542-552.

BP 2009, BP Statistical Review of World Energy June 2009, Beacon Press, Londres.

Environmental Protection Agency 2002, A Comprehensive Analysis of Biodiesel Impacts on Exhaust Emissions, United States Environmental Protection Agency, Washington.

European Biodiesel Board 2009, Statistics: The EU biodiesel industry, disponível em: http://www.ebb-eu.org/ stats.php

Fangrui, M. \& Milford, A. H. 1999, «Biodiesel production: a review», Bioresource Technology, no 70, pp. 1-15.

Inovação e Projectos em Ambiente 2004, Linhas de definição estratégica do sistema de gestão dos óleos alimentares usados, Instituto dos Resíduos, Lisboa.

Lima, P. C. 2004, O Biodiesel e a Inclusão Social, Estudo de Consultoria Legislativa, Câmara dos Deputados, Brasília.

Maurício, S. S. 2008, A Produção de Biodiesel a partir de Óleos Alimentares Usados, Dissertação para obtenção do grau de Mestre em Engenharia do Ambiente da Universidade de Aveiro, Aveiro.

Methanol Institute and International Fuel Quality Center 2006, A Biodiesel Primer: Market \& Public Policy Developments, Quality, Standards \& Handlin, MI/IFQC, Arlington.

Pedrotti, F. 2006, «Biodiesel - Combustível Ecológico», Enciclopédia Biosfera, no 02, pp. 1-26.

Torres, E. A., Chirinos, H., Alves, C., Santos, D. \& Camelier, L. 2006, «Biodiesel: o combustível para o novo século", Revista Bahia Análise \& Dados, no 16, pp. 89-95.

Zhang, Y., Dubé, M.A., McLean, D.D. \& Kates, M. 2003, «Biodiesel production from waste cooking oil: 1. Process design and technological assessment», Bioresource Technology, no 89, pp. 1-16. 